\title{
Chemical applicability of Gourava and hyper-Gourava indices
}

\author{
B. Basavanagoud, Shruti Policepatil \\ Department of Mathematics, Karnatak University, Dharwad - 580 003, Karnataka, India \\ b.basavanagoud@gmail.com, shrutipatil300@gmail.com
}

DOI 10.17586/2220-8054-2021-12-2-142-150

\begin{abstract}
Topological indices are extensively used as molecular descriptors in building Quantitative Structure-Activity Relationship (QSAR), Quantitative Structure-Property Relationship (QSPR) and Quantitative Structure-Toxicity Relationship (QSTR). In this paper, Gourava and hyper-Gourava indices are tested with physico-chemical properties of octane isomers such as entropy, acentric factor and DHVAP using linear regression models. The first Gourava index highly correlates with entropy (coefficient of correlation 0.9644924) and the second Gourava index highly correlates with acentric factor (coefficient of correlation 0.962243). Further, Gourava and hyper-Gourava indices are obtained for the line graph of subdivision graph of 2D-lattice, nanotube and nanotorus of $\mathrm{TUC}_{4} \mathrm{C}_{8}[p, q]$.
\end{abstract}

Keywords: topological indices, Gourava indices, hyper-Gourava indices, 2D-lattice of $T U C_{4} C_{8}[p, q], T U C_{4} C_{8}[p, q]$ nanotube, $T U C_{4} C_{8}[p, q]$ nanotorus.

Received: 12 March 2021

Revised: 17 March 2021

\section{Introduction}

Let $G=(V, E)$ be a graph with a vertex set $V(G)$ and an edge set $E(G)$ such that $|V(G)|=n$ and $|E(G)|=m$. The degree of a vertex $d_{G}(v)$ is the number of edges incident to it in $G$. For undefined graph theoretic terminologies and notations refer to [1] or [2]. The line graph [1] $L(G)$ of a graph $G$ with vertex set as the edge set of $G$ and two vertices of $L(G)$ are adjacent whenever the corresponding edges in $G$ have a vertex incident in common. The subdivision graph [1] $S(G)$ of a graph $G$ whose vertex set is $V(G) \cup E(G)$ where two vertices are adjacent if and only if one is a vertex of $G$ and other is an edge of $G$ incident with it.

Topological indices promise to have far-reaching applications in drug design, cancer research and bonding theory etc. Among them, first degree based topological index is first Zagreb index developed in 1972 [3]. Further, the second Zagreb index [4] and F-index [5] were studied. Motivated by the definitions of the Zagreb indices and their wide applications, Kulli introduced the first Gourava index and second Gourava index of a molecular graph [6] as follows:

$$
\begin{aligned}
G O_{1}(G) & =\sum_{u v \in E(G)}\left[d_{G}(u)+d_{G}(v)+d_{G}(u) d_{G}(v)\right], \\
G O_{2}(G) & =\sum_{u v \in E(G)}\left[\left(d_{G}(u)+d_{G}(v)\right)\left(d_{G}(u) d_{G}(v)\right)\right] .
\end{aligned}
$$

In [7], Kulli introduced the first and second hyper-Gourava indices of a molecular graph $G$ which are defined as:

$$
\begin{aligned}
H G O_{1}(G) & =\sum_{u v \in E(G)}\left[d_{G}(u)+d_{G}(v)+d_{G}(u) d_{G}(v)\right]^{2}, \\
H G O_{2}(G) & =\sum_{u v \in E(G)}\left[\left(d_{G}(u)+d_{G}(v)\right)\left(d_{G}(u) d_{G}(v)\right)\right]^{2} .
\end{aligned}
$$

Alkanes are the important organic compounds classified under hydrocarbons and they are saturated, that is the carbon backbone consists of carbon to carbon single bonds only. There are a wide variety of alkanes that play vital roles in our daily life. Alkanes are used in LPG (Liquefied Petroleum Gas), propellants, disposable lighters etc. Alkanes containing 5-8 carbon atoms are used as fuel and as good solvents for nonpolar substances. For this purpose, they are widely used in industries and research work. Two or more compounds having same molecular formula but different chemical structures are called isomers. Eighteen isomers of octane are depicted in Fig. 1.

A nanostructure is an object that has at least one dimension equal to or smaller than 100 nanometers. There are various types of nanostructures such as nanoparticles, nanotubes and nanopores etc., In the last few years, much research has been concentrated on the use of nanostructures towards problems of biology and medicine. Topological index of $T U R C_{4} C_{8}(S)$ nanotube, armchair polyhex nanotube, V-phenylenic nanotube and V-phenylenic nanotori are discussed in [8]. For more discussion on nanostructures, readers are referred to [9-11]. 


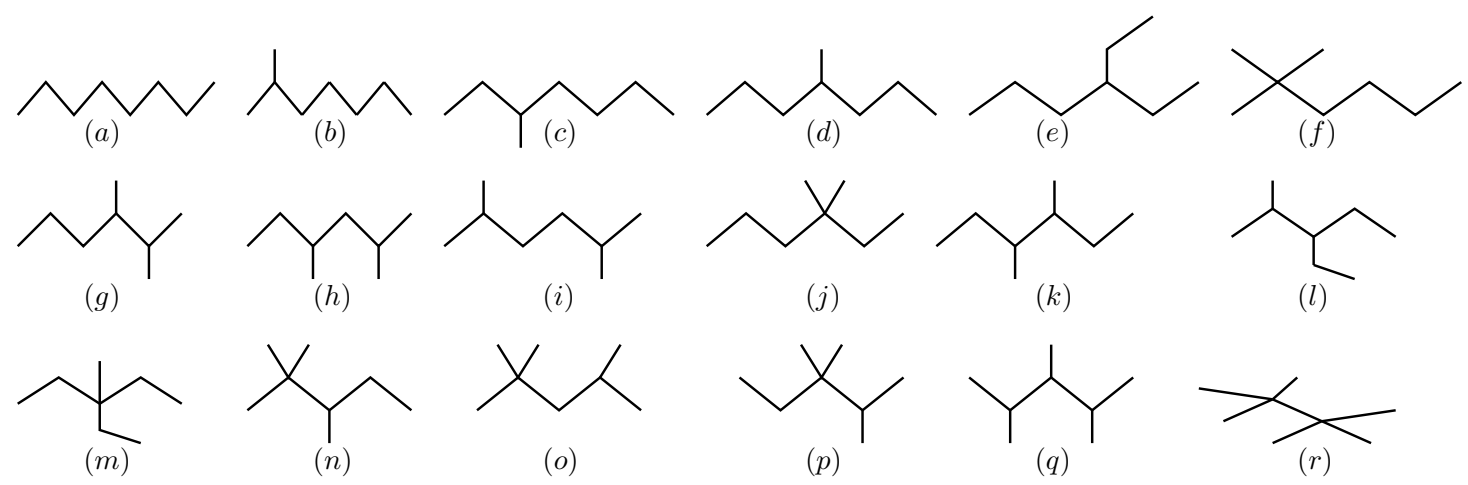

FIG. 1. (a) n-octane; (b) 2-methyl heptane; (c) 3-methyl heptane; (d) 4-methyl heptane; (e) 3ethyl hexane; (f) 2,2-dimethyl hexane; (g) 2,3-dimethyl hexane; (h) 2,4-dimethyl hexane; (i) 2,5dimethyl hexane; (j) 3,3-dimethyl hexane; (k) 3,4-dimethyl hexane; (l) 3-ethyl-2-methyl pentane; (m) 3-ethyl-3-methyl pentane; (n) 2,2,3-trimethyl pentane; (o) 2,2,4-trimethyl pentane; (p) 2,3,3trimethyl pentane; (q) 2,3,4-trimethyl pentane; (r) 2,2,3,3-tetramethyl butane.

\section{Chemical applicability of Gourava and hyper-Gourava indices}

In this section, we present a linear regression model of these physical properties with the Gourava and hyperGourava indices. Gourava and hyper-Gourava indices are degree based indices. These indices have good correlation with physical properties of chemical compounds like entropy $(S)$, acentric factor (AcentFac) and standard enthalpy of vaporization (DHVAP) of octane isomers. Gourava and hyper-Gourava indices are tested using a data set of octane isomers found at http: / / www. moleculardescriptors. eu/dataset. htm. The columns 5, 6, 7 and 8 of Table 2 are computed by using the definition of first Gourava index, second Gourava index, first hyper-Gourava index and second hyper-Gourava index, respectively.

The linear regression models for entropy, acentic factor and DHVAP using the data of Tables 2 are obtained using the least squares fitting procedure as implemented in R software [12].

Gourava indices values against entropy, acentric factor and DHVAP values are plotted in Figs. 2, 4 and 6. HyperGourava indices values against entropy, acentric factor and DHVAP values are plotted in Figs. 3, 5 and 7.
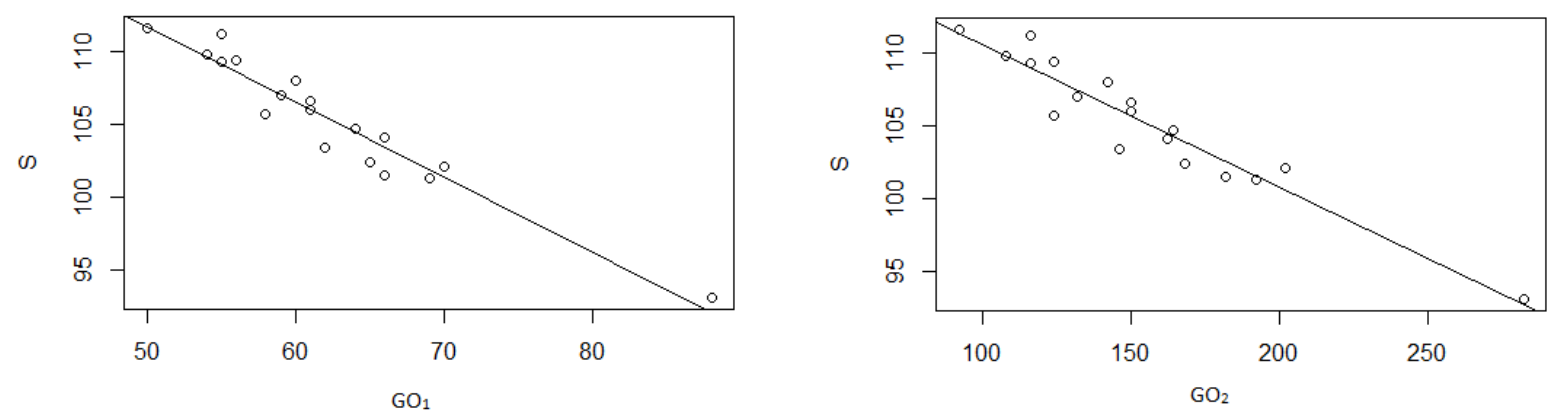

FIG. 2. Scatter diagram of $S$ on $G O_{1}$ (left) and $\mathrm{GO}_{2}$ (right), superimposed by the fitted regression line

The fitted models for $G O_{1}$ are:

$$
\begin{gathered}
S=137.6( \pm 2.2)-0.52( \pm 0.04) G O_{1}, \\
\text { AcentFac }=0.6( \pm 0.02)-0.004( \pm 0.0003) G O_{1}, \\
D H V A P=11.5( \pm 0.4)-0.04( \pm 0.006) G O_{1} .
\end{gathered}
$$

The fitted models for $\mathrm{GO}_{2}$ are:

$$
\begin{gathered}
S=120.5( \pm 1.2)-0.1( \pm 0.008) G O_{2}, \\
\text { AcentFac }=0.5( \pm 0.009)-0.0008( \pm 0.00006) G O_{2}, \\
D H V A P=10.2( \pm 0.2)-0.007( \pm 0.001) G O_{2} .
\end{gathered}
$$


TABLE 1. Experimental values of entropy, acentric factor, DHVAP and the corresponding values of first Gourava index, second Gourava index, first hyper-Gourava index and second hyper-Gourava index of octane isomers

\begin{tabular}{|c|c|c|c|c|c|c|c|}
\hline Alkane & $\mathrm{S}$ & AcentFac & DHVAP & $G O_{1}$ & $G O_{2}$ & $H G O_{1}$ & $H G O_{2}$ \\
\hline$n$-octane & 111.67 & 0.397898 & 9.915 & 50 & 92 & 370 & 1352 \\
\hline 2-methyl-heptane & 109.84 & 0.377916 & 9.484 & 54 & 108 & 436 & 1992 \\
\hline 3-methyl-heptane & 111.26 & 0.371002 & 9.521 & 55 & 116 & 469 & 2528 \\
\hline 4-methyl-heptane & 109.32 & 0.371504 & 9.483 & 55 & 116 & 469 & 2528 \\
\hline 3-ethyl-hexane & 109.43 & 0.362472 & 9.476 & 56 & 124 & 502 & 3064 \\
\hline 2, 2-dimethyl-hexane & 103.42 & 0.339426 & 8.915 & 62 & 146 & 592 & 4052 \\
\hline 2, 3-dimethyl-hexane & 108.02 & 0.348247 & 9.272 & 60 & 142 & 582 & 4540 \\
\hline 2, 4-dimethyl-hexane & 106.98 & 0.344223 & 9.029 & 59 & 132 & 535 & 3168 \\
\hline 2, 5-dimethyl-hexane & 105.72 & 0.35683 & 9.051 & 58 & 124 & 502 & 2632 \\
\hline 3, 3-dimethyl-hexane & 104.74 & 0.322596 & 8.973 & 64 & 164 & 668 & 5736 \\
\hline 3, 4-dimethyl-hexane & 106.59 & 0.340345 & 9.316 & 61 & 150 & 615 & 5076 \\
\hline 2-methyl-3-ethyl-pentane & 106.06 & 0.332433 & 9.209 & 61 & 150 & 615 & 5076 \\
\hline 3-methyl-3-ethyl-pentane & 101.48 & 0.306899 & 9.081 & 66 & 182 & 744 & 7420 \\
\hline 2, 2, 3-trimethyl-pentane & 101.31 & 0.300816 & 8.826 & 69 & 192 & 799 & 9336 \\
\hline 2, 2, 4-trimethyl-pentane & 104.09 & 0.30537 & 8.402 & 66 & 162 & 658 & 4692 \\
\hline 2, 3, 3-trimethyl-pentane & 102.06 & 0.293177 & 8.897 & 70 & 202 & 842 & 3428 \\
\hline 2, 3, 4-trimethyl-pentane & 102.39 & 0.317422 & 9.014 & 65 & 168 & 695 & 6552 \\
\hline 2, 2, 3, 3-tetramethyl-butane & 93.06 & 0.255294 & 8.41 & 88 & 282 & 1202 & 20724 \\
\hline
\end{tabular}
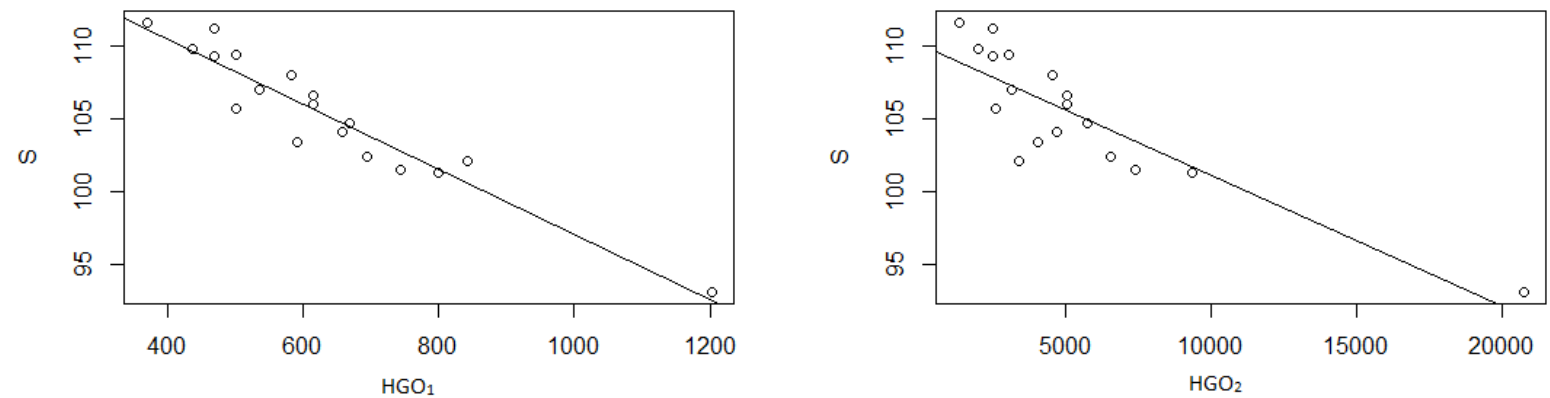

FIG. 3. Scatter diagram of $S$ on $H G O_{1}$ (left) and $\mathrm{HGO}_{2}$ (right), superimposed by the fitted regression line 

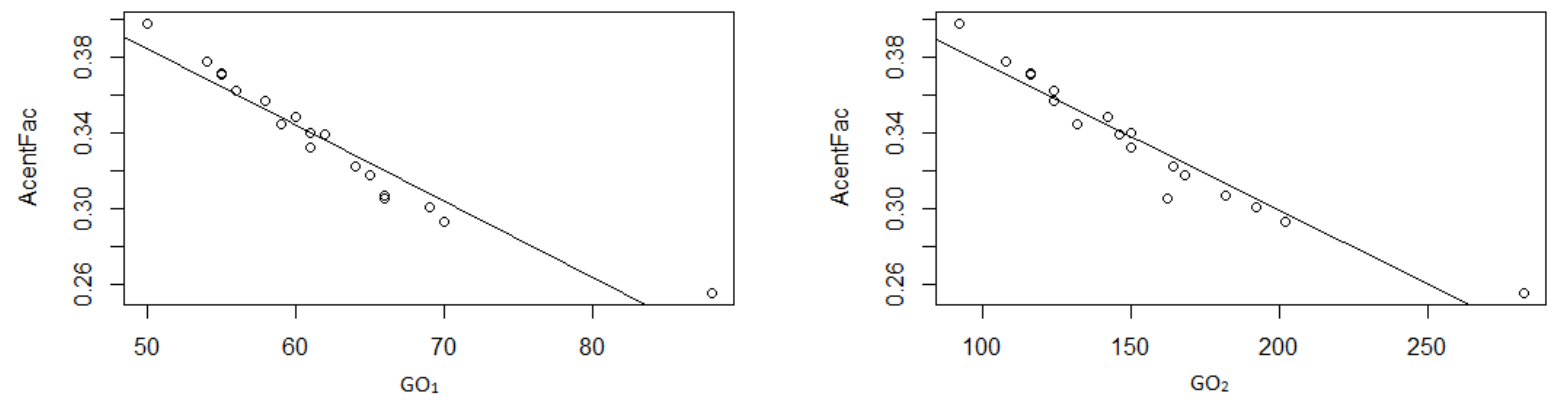

FIG. 4. Scatter diagram of Acent Fac on $G O_{1}$ (left) and $G O_{2}$ (right), superimposed by the fitted regression line
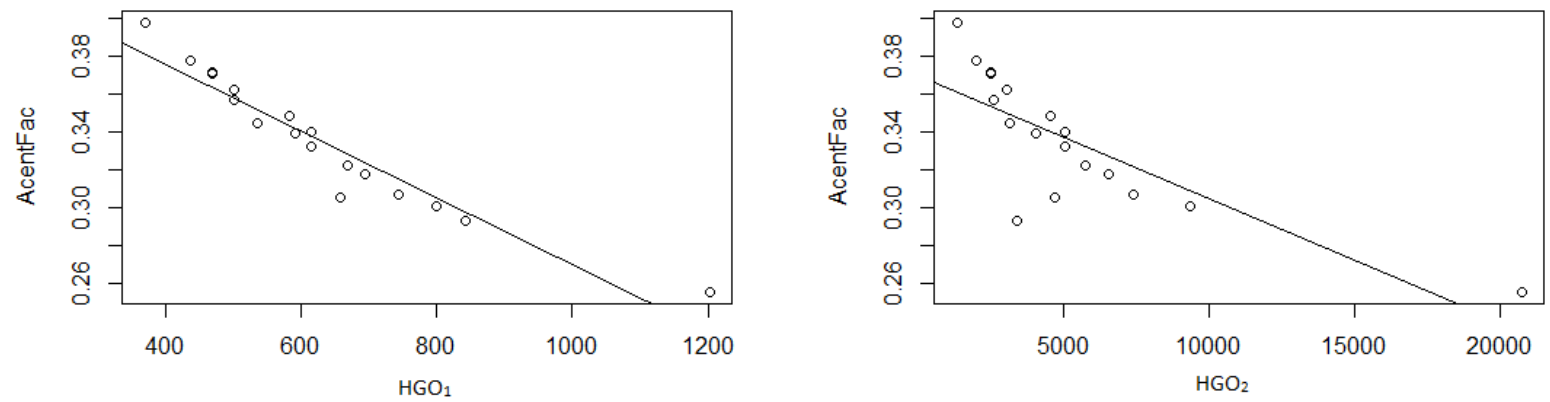

FIG. 5. Scatter diagram of Acent Fac on $\mathrm{HGO}_{1}$ (left) and $\mathrm{HGO}_{2}$ (right), superimposed by the fitted regression line
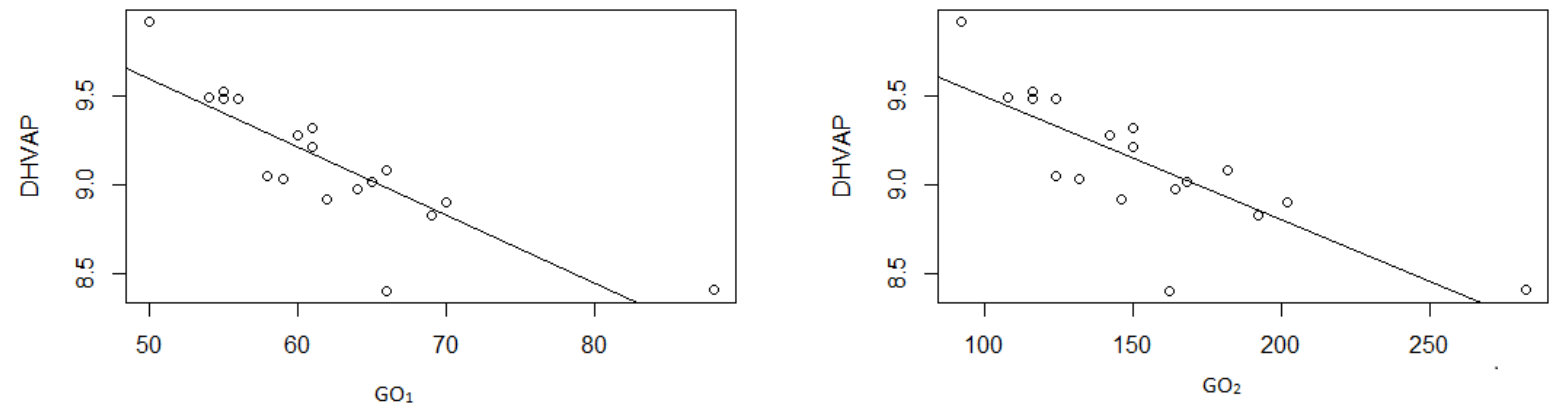

FIG. 6. Scatter diagram of DHVAP on $G O_{1}$ (left) and $G O_{2}$ (right), superimposed by the fitted regression line
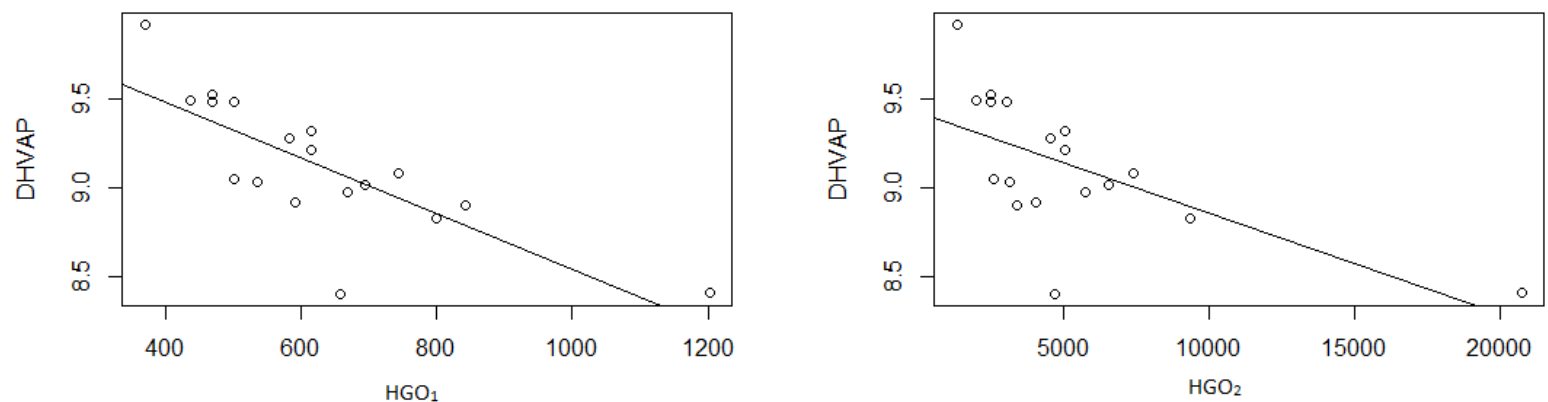

FIG. 7. Scatter diagram of DHVAP on $\mathrm{HGO}_{1}$ (left) and $\mathrm{HGO}_{2}$ (right), superimposed by the fitted regression line 
The fitted models for $H G O_{1}$ are:

$$
\begin{gathered}
S=119.5( \pm 1.2)-0.02( \pm 0.002) H G O_{1}, \\
\text { AcentFac }=0.4( \pm 0.009)-(0.0002)( \pm 0.00001) H G O_{1}, \\
D H V A P=10.1( \pm 0.2)-0.002( \pm 0.0003) H G O_{1} .
\end{gathered}
$$

The fitted models for $\mathrm{HGO}_{2}$ are:

$$
\begin{gathered}
S=110.1( \pm 0.9)-0.0009( \pm 0.0001) \mathrm{HGO}_{2}, \\
\text { AcentFac }=0.4( \pm 0.01)-0.00001( \pm 0.000001) \mathrm{HGO}_{2}, \\
D H V A P=9.4( \pm 0.1)-0.00006( \pm 0.00002) \mathrm{HGO}_{2} .
\end{gathered}
$$

Note: The values in brackets of Eqns. (2.1) to (2.12) are the corresponding standard errors of the regression coefficients. The index is better as $|r|$ approaches 1 .

From Table 2, Figs. 2, 4 and 6 we can observe that $G O_{1}$ correlates highly with entropy and the correlation coefficient $|r|=0.9644924$. Also, $G O_{1}$ has good correlation $(|r|>0.9)$ with Acentric Factor and $(|r|>0.8)$ with DHVAP.

From Table 3, Figs. 2, 4 and 6 we can observe that $\mathrm{GO}_{2}$ correlates highly with Acentric Factor and the correlation coefficient $|r|=0.9644924$. Also, $G O_{2}$ has good correlation $(|r|>0.9)$ with entropy and $(|r|>0.75)$ with DHVAP.

From Table 4, Figs. 3, 5 and 7 we can observe that $H G O_{1}$ correlates highly with Acentric Factor and the correlation coefficient $|r|=0.9554303$. Also, $H G O_{1}$ has good correlation $(|r|>0.9)$ with entropy and $(|r|>0.75)$ with DHVAP.

From Table 5, Figs. 3, 5 and $7 \mathrm{HGO}_{2}$ has good correlation $(|r|>0.85)$ with entropy, $(|r|>0.75)$ with Acentric Factor and $(|r|>0.6)$ with DHVAP.

TABLE 2. Correlation coefficient and residual standard error of regression models for $G O_{1}$

\begin{tabular}{|c|c|c|}
\hline Physical properties & Absolute value of the correlation coefficient $(|r|)$ & Residual standard error \\
\hline Entropy & 0.9644924 & 1.23 \\
Acentric Factor & 0.9595891 & 0.01028 \\
DHVAP & 0.8368024 & 0.2163 \\
\hline
\end{tabular}

TABLE 3. Correlation coefficient and residual standard error of regression models for $\mathrm{GO}_{2}$

\begin{tabular}{|c|c|c|}
\hline Physical properties & Absolute value of the correlation coefficient $(|r|)$ & Residual standard error \\
\hline Entropy & 0.9561406 & 1.364 \\
Acentric Factor & 0.962243 & 0.009946 \\
DHVAP & 0.7896431 & 0.2424 \\
\hline
\end{tabular}

TABLE 4. Correlation coefficient and residual standard error of regression models for $H G O_{1}$

\begin{tabular}{|c|c|c|}
\hline Physical properties & Absolute value of the correlation coefficient $(|r|)$ & Residual standard error \\
\hline Entropy & 0.953055 & 1.41 \\
Acentric Factor & 0.9554303 & 0.01079 \\
DHVAP & 0.779148 & 0.2477 \\
\hline
\end{tabular}


TABLE 5. Correlation coefficient and residual standard error of regression models for $\mathrm{HGO}_{2}$

\begin{tabular}{|c|c|c|}
\hline Physical properties & Absolute value of the correlation coefficient $(|r|)$ & Residual standard error \\
\hline Entropy & 0.8691773 & 2.303 \\
Acentric Factor & 0.798397 & 0.022 \\
DHVAP & 0.6442586 & 0.3022 \\
\hline
\end{tabular}

\section{Gourava and hyper-Gourava indices of line graph of subdivision graphs of 2D-lattice, nanotube and} nanotorus of $\mathrm{TUC}_{4} C_{8}[p, q]$

In this section, we obtain the Gourava and hyper-Gourava indices of line graph of subdivision graphs of 2D-lattice, nanotube and nanotorus of $T U C_{4} C_{8}[p, q]$. Let $p$ and $q$ denote the number of squares in a row and the number of rows of squares, respectively in 2D-lattice, nanotube and nanotorus of $T U C_{4} C_{8}[4,3]$ as shown in Fig 8 (a), (b) and (c) respectively.

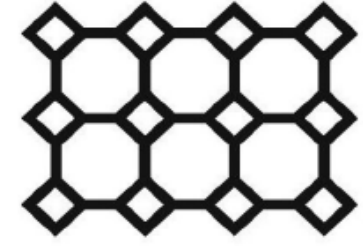

(a)

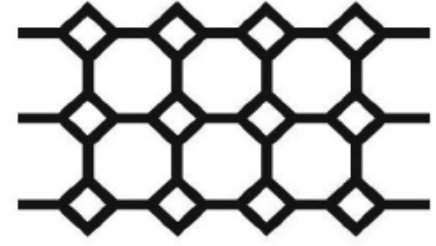

(b)

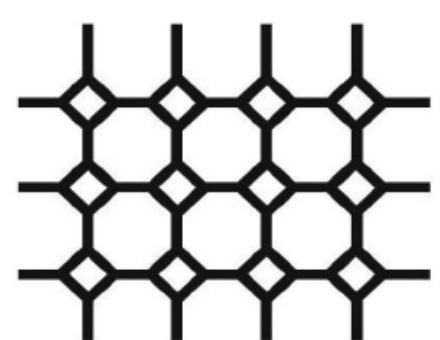

(c)

FIG. 8. (a) 2D-lattice of $T U C_{4} C_{8}[4,3]$; (b) $T U C_{4} C_{8}[4,3]$ nanotube; (c) $T U C_{4} C_{8}[4,3]$ nanotorus

The number of vertices and edges of 2D-lattice, nanotube and nanotorus of $T U C_{4} C_{8}[p, q]$ are given in Table 6 .

TABLE 6. Order and size of graphs

\begin{tabular}{|c|c|c|}
\hline Graph & Order & Size \\
\hline 2D-lattice of $T U C_{4} C_{8}[p, q]$ & $4 p q$ & $6 p q-p-q$ \\
$T U C_{4} C_{8}[p, q]$ Nanotube & $4 \mathrm{pq}$ & $6 \mathrm{pq}-\mathrm{p}$ \\
$T U C_{4} C_{8}[p, q]$ Nanotorus & $4 \mathrm{pq}$ & $6 \mathrm{pq}$ \\
\hline
\end{tabular}

For more details about topological indices of the line graph of subdivision graphs of 2D-lattice, nanotube and nanotorus of $T U C_{4} C_{8}[p, q]$, refer [9-11].

The following theorem gives the Gourava and hyper-Gourava indices of line graph of subdivision graphs of 2Dlattice of $T U C_{4} C_{8}[p, q]$.

Theorem 3.1. Let $A$ be the line graph of the subdivision graph of $2 D$-lattice of $T U C_{4} C_{8}[p, q]$ (See Fig. 9). Then

1. $G O_{1}(A)=270 p q-105(p+q)+4$,

2. $G O_{2}(A)=972 p q-442(p+q)+40$,

3. $H G O_{1}(A)=4050 p q-1863(p+q)+188$,

4. $\mathrm{HGO}_{2}(A)=52488 p q-27964(p+q)+5488$.

Proof. Let $A$ be the line graph of the subdivision graph of 2D-lattice of $T U C_{4} C_{8}[p, q]$. The graph $A$ has $2(6 p q-6-q)$ vertices and $18 p q-5 p-5 q$ edges. 
1. By using definition of first Gourava index and information in Table 7, we have:

$$
\begin{aligned}
G O_{1}(A) & =\sum_{(u, v) \in E(A)}\left[\left(d_{A}(u)+d_{A}(v)\right)+\left(d_{A}(u) d_{A}(v)\right)\right] \\
& =\left|E_{2,2}\right|[(2+2)+(2 \times 2)]+\left|E_{2,3}\right|[(2+3)+(2 \times 3)]+\left|E_{3,3}\right|[(3+3)+(3 \times 3)] \\
& =2(p+q+2)(4+4)+4(p+q-2)(5+6)+(18 p q-11 p-11 q+4)(6+9) \\
& =270 p q-105(p+q)+4 .
\end{aligned}
$$

2. By using definition of second Gourava index and information in Table 7, we have:

$$
\begin{aligned}
G O_{2}(A) & =\sum_{(u, v) \in E(A)}\left[\left(d_{A}(u)+d_{A}(v)\right)\left(d_{A}(u) d_{A}(v)\right)\right] \\
& =\left|E_{2,2}\right|[(2+2)(2 \times 2)]+\left|E_{2,3}\right|[(2+3)(2 \times 3)]+\left|E_{3,3}\right|[(3+3)(3 \times 3)] \\
& =2(p+q+2)(4 \times 4)+4(p+q-2)(5 \times 6)+(18 p q-11 p-11 q+4)(6 \times 9) \\
& =972 p q-442(p+q)+40 .
\end{aligned}
$$

3. By using definition of first hyper-Gourava index and information in Table 7, we have:

$$
\begin{aligned}
H G O_{1}(A) & =\sum_{(u, v) \in E(A)}\left[\left(d_{A}(u)+d_{A}(v)\right)+\left(d_{A}(u) d_{A}(v)\right)\right]^{2} \\
& =\left|E_{2,2}\right|[(2+2)+(2 \times 2)]^{2}+\left|E_{2,3}\right|[(2+3)+(2 \times 3)]^{2}+\left|E_{3,3}\right|[(3+3)+(3 \times 3)]^{2} \\
& =2(p+q+2)(4+4)^{2}+4(p+q-2)(5+6)^{2}+(18 p q-11 p-11 q+4)(6+9)^{2} \\
& =4050 p q-1863(p+q)+188 .
\end{aligned}
$$

4. By using definition of second hyper-Gourava index and information in Table 7, we have:

$$
\begin{aligned}
H G O_{2}(A) & =\sum_{(u, v) \in E(A)}\left[\left(d_{A}(u)+d_{A}(v)\right)\left(d_{A}(u) d_{A}(v)\right)\right]^{2} \\
& =\left|E_{2,2}\right|[(2+2)(2 \times 2)]^{2}+\left|E_{2,3}\right|[(2+3)(2 \times 3)]^{2}+\left|E_{3,3}\right|[(3+3)(3 \times 3)]^{2} \\
& =2(p+q+2)(4 \times 4)^{2}+4(p+q-2)(5 \times 6)^{2}+(18 p q-11 p-11 q+4)(6 \times 9)^{2} \\
& =52488 p q-27964(p+q)+5488 .
\end{aligned}
$$

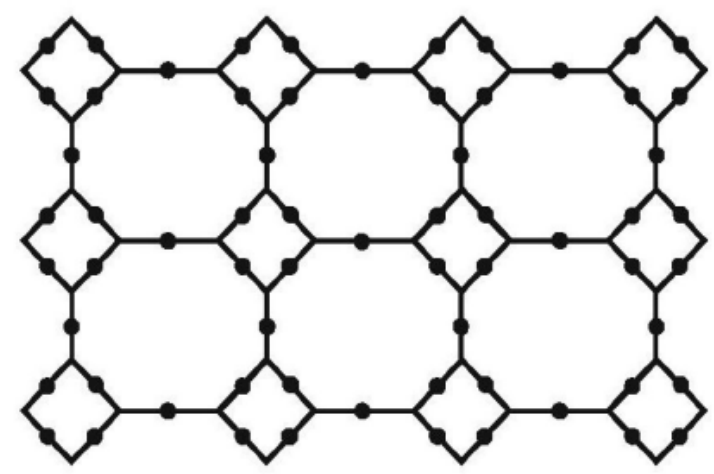

(a)

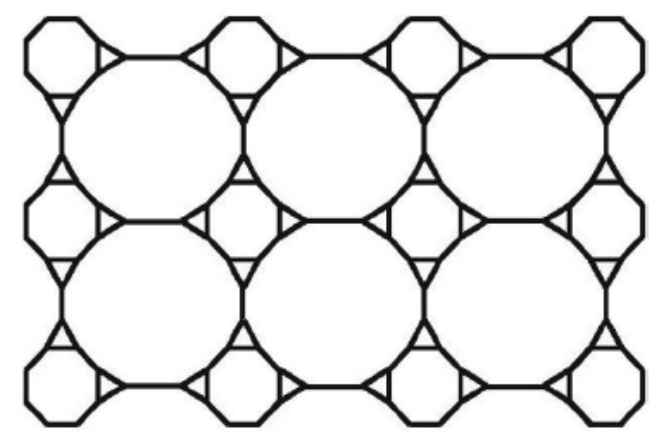

(b)

FIG. 9. (a) Subdivision graph of 2D-lattice of $T U C_{4} C_{8}[4,3]$; (b) Line graph of the subdivision graph of 2D-lattice of $T U C_{4} C_{8}[4,3]$

The following theorem gives the Gourava and hyper-Gourava indices of line graph of subdivision graphs of $T U C_{4} C_{8}[p, q]$ of nanotube. 
TABLE 7. The edge partition of $A$ based on degree of each edge

\begin{tabular}{|c|c|c|c|}
\hline$d_{A}(u), d_{A}(v): u v \in E(A)$ & $(2,2)$ & $(2,3)$ & $(3,3)$ \\
\hline Number of edges & $2(p+q+2)$ & $4(p+q-2)$ & $18 p q-11 p-11 q+4$ \\
\hline
\end{tabular}

Theorem 3.2. Let $B$ be the line graph of the subdivision graph of $T U C_{4} C_{8}[p, q]$ nanotube (See Fig. 10). Then

1. $G O_{1}(B)=270 p q-105 p$,

2. $G O_{2}(B)=972 p q-442 p$,

3. $H G O_{1}(B)=4050 p q-1863 p$,

4. $\mathrm{HGO}_{2}(B)=52488 p q-27964 p$.

Proof. By using the definition of Gourava and hyper-Gourava indices and information given in Table 8, we obtain the desired result.

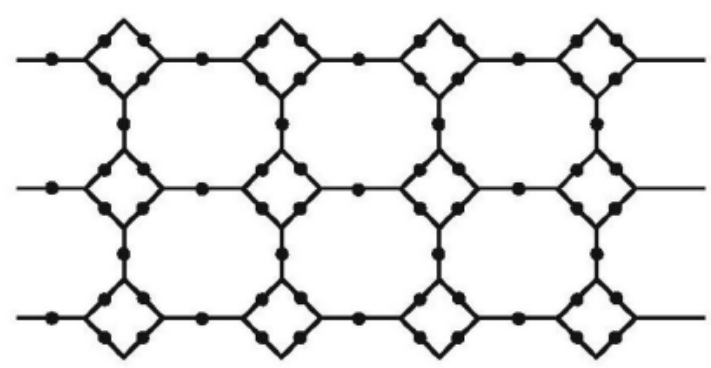

(a)

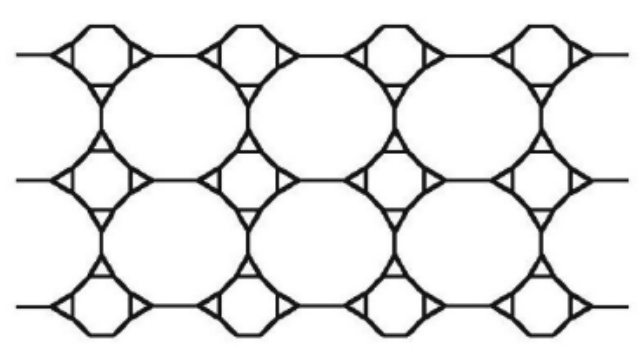

(b)

FIG. 10. (a) Subdivision graph of $T U C_{4} C_{8}[4,3]$ of nanotube; (b) Line graph of the subdivision graph of $\mathrm{TUC}_{4} \mathrm{C}_{8}[4,3]$ of nanotube

TABLE 8. The edge partition of $B$ based on degree of each edge

\begin{tabular}{|c|c|c|c|}
\hline$d_{B}(u), d_{B}(v): u v \in E(B)$ & $(2,2)$ & $(2,3)$ & $(3,3)$ \\
\hline Number of edges & $2 p$ & $4 p$ & $18 p q-11 p$ \\
\hline
\end{tabular}

The following theorem gives the Gourava and hyper-Gourava indices of line graph of subdivision graphs of $T U C_{4} C_{8}[p, q]$ of nanotorus.

Theorem 3.3. Let $C$ be the line graph of the subdivision graph of $T U C_{4} C_{8}[p, q]$ nanotorus (See Fig. 11). Then

1. $G O_{1}(C)=270 p q$,

2. $G O_{2}(C)=972 p q$,

3. $H G O_{1}(C)=4050 p q$,

4. $\mathrm{HGO}_{2}(\mathrm{C})=52488 p q$.

Proof. By using the definition of Gourava and hyper-Gourava indices and information given in Table 9, we obtain the desired result.

TABLE 9. The edge partition of $C$ based on degree of each edge

\begin{tabular}{|c|c|}
\hline$d_{C}(u), d_{C}(v): u v \in E(C)$ & $(3,3)$ \\
\hline Number of edges & $18 p q$ \\
\hline
\end{tabular}




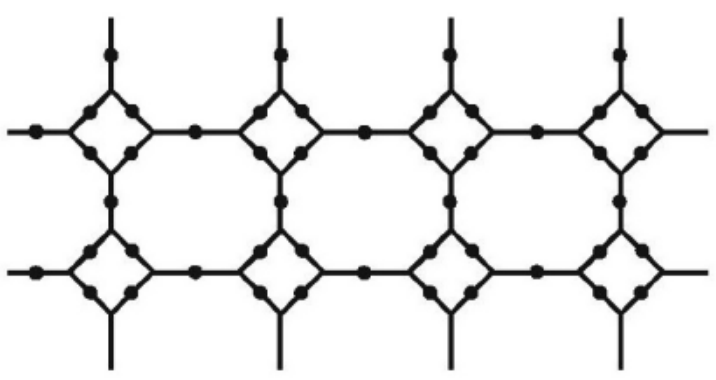

(a)

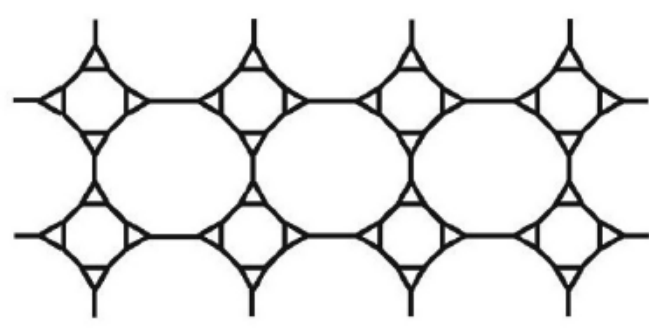

(b)

FIG. 11. (a) Subdivision graph of $T U C_{4} C_{8}[4,3]$ of nanotorus; (b) Line graph of the subdivision graph of $T U C_{4} C_{8}[4,3]$ of nanotorus

\section{Conclusion}

In this paper, we have studied the chemical applicability of Gourava and hyper-Gourava indices. These indices show good correlation with physico-chemical properties. The first Gourava index highly correlates with entropy (coefficient of correlation is 0.9644924 and residual standard error is 1.23 ) which is better than the modified first Kulli-Basava index $(|r|=0.9476403$ and residual standard error is 1.363) [13], the first Kulli-Basava index $(|r|=$ 0.956207 and residual standard error is 1.415) [13] and the first neighbourhood Zagreb index $(|r|=0.9526144$ and residual standard error is 1.416) [14]. The second Gourava index highly correlates with acentric factor (coefficient of correlation is 0.962243 and residual standard error is 0.009946$)$ which is better than $(\beta, \alpha)$ connectivity index $(|r|=0.95802$ and residual standard error is 0.01047$)$ [15]. In addition, we computed Gourava and hyper-Gourava indices of the line graph of subdivision graph of 2D-lattice, nanotube and nanotorus of $T U C_{4} C_{8}[p, q]$. These results would help to understand the chemical reactivity and biological activity of the nanostructures.

\section{Acknowledgements}

B. Basavanagoud is supported by the University Grants Commission (UGC), New Delhi, through UGC-SAP DRS-III for 2016-2021: F.510/3/DRS-III/2016(SAP-I).

\section{References}

[1] Harary F. Graph Theory, Addison-Wesely, Reading Mass, 1969.

[2] Kulli V.R. College Graph Theory, Vishwa Int. Publ., Gulbarga, India, 2012.

[3] Gutman I., Trinajstić N. Graph theory and molecular orbitals, Total $\pi$-electron energy of alternant hydrocarbons. Chem. Phys. Lett., 1972, 17 (4), P. 535-538.

[4] Gutman I., Ruščić B., Trinajstić N., Wilcox C.F. Graph theory and molecular orbitals. XII. Acyclic polyenes. J. Chem. Phys., 1975, 62, P. 3399-3405.

[5] Furtula B., Gutman I. A forgotten topological index. J. Math. Chem., 2015, 53 (4), P. 1184-1190.

[6] Kulli V.R. The Gourava indices and coindices of graphs. Annals of Pure and Applied Mathematics, 2017,14 (1), P. $33-38$.

[7] Kulli V.R. On hyper-Gourava indices and coindices. Int. Journal of Mathematical Archieve, 2017, 8 (12), P. 116-120.

[8] Mondal S., Bhosale A., De N., Pal A. Topological properties of some nanostructures. Nanosystems: Physics, Chemistry, Mathematics, 2020, 11 (1), P. 14-24.

[9] Hosamani S.M. Computing Sanskruti index of certain nanostructures. J. Appl. Math. Comput., 2017, 54, P. 425-433.

[10] Nadeem M.F., Zafar S., Zahid Z., On certain topological indices of the line graph of subdivision graphs. Appl. Math. Comput., 2015, 271, P. 790-794.

[11] Nadeem M.F., Zafar S., Zahid Z. On topological properties of the line graph of subdivision graphs of certain nanostructures. Appl. Math. Comput., 2016, 273, P. 125-130.

[12] R Core Team. R: A language and environment for statistical computing. R Foundation for Statistical Computing, Vienna, Austria, 2016, URL : https://www.R-project.org/.

[13] Basavanagoud B., Jakkannavar P. Kulli-Basava indices of graphs. Int. J. Appl. Eng. Res., 2019, 14 (1), P. $325-342$.

[14] Basavanagoud B., Barangi A.P., Hosamani S.M. First neighbourhood Zagreb index of some nanostructures. Proc. Inst. Appl. Math., 2018, 7 (2), P. 178-193.

[15] Basavanagoud B., Desai V., Patil S. $(\beta, \alpha)$ connectivity index of graphs. Appl. Math. Nonlinear Sci., 2017, 2 (1), P. $21-30$. 